\title{
GMR
}

\section{Effect of increased UV-B radiation on carotenoid accumulation and total antioxidant capacity in tobacco (Nicotiana tabacum L.) leaves}

\author{
J. Shen, C.Q. Jiang, Y.F. Yan, B.R. Liu and C.L. Zu \\ Tobacco Research Institute, Anhui Academy of Agricultural Sciences, \\ Hefei City, Anhui Province, China \\ Corresponding author: C.L. $\mathrm{Zu}$ \\ E-mail: 1cz2468@sina.com \\ Genet. Mol. Res. 16 (1): gmr16018438 \\ Received January 13, 2016 \\ Accepted January 10, 2017 \\ Published March 8, 2017 \\ DOI http://dx.doi.org/10.4238/gmr16018438 \\ Copyright $(\underset{2}{ } 2017$ The Authors. This is an open-access article distributed under the terms of \\ the Creative Commons Attribution ShareAlike (CC BY-SA) 4.0 License.
}

\begin{abstract}
Carotenoids are important components of plant antioxidant systems, which protect photosystems from photooxidative destruction during ultraviolet-B (UV-B) exposure. The influence of carotenoids on total antioxidant capacity (TAC) of plants has rarely been studied. In this study, tobacco (Nicotiana tabacum L., 'K326') seedlings exposed to UV-B radiation were used in order to evaluate the effects of ambient levels of UV-B radiation on carotenoid accumulation. The aim was to investigate whether carotenoids could enhance TAC as a means of UV protection. Our results showed that leaf carotenoid content in the low UV-B exposure $\left(+9.75 \mu \mathrm{W} / \mathrm{cm}^{2}\right)$ plants was approximately $8 \%$ higher than that observed in control plants at 2-8 days of exposure. At high UV-B exposure $\left(+20.76 \mu \mathrm{W} / \mathrm{cm}^{2}\right)$, the carotenoid content increased rapidly after 1 day's exposure $(10.41 \%$ higher than the control), followed by a return to the content as in control plants. Furthermore, carotenoid content positively correlated with TAC
\end{abstract}

Genetics and Molecular Research 16 (1): gmr16018438 
$(\mathrm{P}=0.024)$. These results suggest that carotenoids have antioxidant properties and play an important role in the antioxidant system. UV-B exposure increased the carotenoid synthesis capability of plants. The plants could deplete the carotenoids to scavenge excess ROS at high UV-B radiation levels, which protects the tobacco plant from oxidative damage caused by UV-B stress.

Key words: UV-B radiation; Carotenoids; Reactive oxygen species; Total antioxidant capacity; Tobacco seedling

\section{INTRODUCTION}

Living organisms in the biosphere are exposed to ultraviolet-B (UV-B, $280 \mathrm{~nm}$ to 320 $\mathrm{nm}$ ) at intensities that vary with the solar angle as well as the thickness of the stratospheric ozone layer. The amount of UV-B depends mainly on latitude and elevation. The intensity of solar UV-B reaching the Earth's surface has continuously increased, because the ozone layer in the stratosphere is depleted. Although UV-B is only a minor component of the total solar radiation $(<0.5 \%)$, even a small increase in intensity can lead to significant biological damage (Zlatev et al., 2012). Exposure to UV-B can influence plant processes in two ways: either by directly

damaging DNA, which can cause heritable mutations, or by eliciting various regulatory effects that cause direct or indirect injuries to plant physiological functions (Lidon, 2012).

At increased UV-B radiation, plant cells produce reactive oxygen species (ROS), such as superoxide anion $\left(\mathrm{O}_{2}^{-}\right)$, hydrogen peroxide $\left(\mathrm{H}_{2} \mathrm{O}_{2}\right)$, and hydroxyl radicals (HO) (Neill et al., 2002). Overproduction of ROS can cause oxidative damage to membrane lipids, nucleic acids, and proteins (Neill et al., 2002). These excessive levels function in mediating UV damage (Strid et al., 1994). Antioxidant defense systems are important to allow plants to survive in UV-B-exposed environments. Plants have developed protective mechanisms against UV-B stress, including enhancement of antioxidant systems (Brosché and Strid, 2003) and accumulation of UV-absorbing compounds (Fedina et al., 2007).

Carotenoids directly protect photosystems against UV radiation (Salama et al., 2011). In plants, carotenoids function as accessory pigments in light harvesting. One of the most important functions of carotenoids is the ability to scavenge various ROS formed under UV-B stress and protect chlorophylls from photooxidation (Karuppanapandian et al., 2011). As an important component of antioxidant systems, carotenoid synthesis is induced by UV-B radiation through an increase in phytoene synthase expression level (Mackerness, 2000). This process is an example of plant acclimation mechanisms that diminish the damaging effects of UV-B radiation. In this process, ROS function as messenger molecules in signaling pathways (Hideg, 2006). Many studies have demonstrated that ROS induce carotenogenesis in some species, such as pepper (Bouvier et al., 1998), poplar (Ballach et al., 1992), and Norway spruce (Polle et al., 1992). However, significant reductions in carotenoids in response to UV-B have been reported in other plant studies (Juozaityte et al., 2008; Indrajith and Ravindran, 2009; Singh et al., 2011). These contradictory results may be attributed to different UV-B oxidative stress levels. Under relatively high oxidative stress, carotenoids are destroyed at a faster rate than they can scavenge the overproduced ROS, resulting in a reduced ability to alleviate UV-B stress (Pallet and Young, 1993). Thus, the relationship between carotenoids and ROS in UV-B radiation is complex.

Genetics and Molecular Research 16 (1): gmr16018438 
Although the effects of UV-B radiation on carotenoid accumulation are welldocumented, the interaction of these pigments with induced ROS remain unclear. This study was performed using tobacco (Nicotiana tabacum L., 'K326') seedlings exposed to UV-B radiation to investigate the effects of enhanced UV-B radiation on carotenoid accumulation, ROS concentration, and total antioxidant capacity (TAC). The purpose of this study was to evaluate the effects of ambient levels of UV-B radiation on the ROS system in tobacco and to test the hypothesis that the carotenoids would lead to enhanced antioxidant capacity as the means of UV-protection.

\section{MATERIAL AND METHODS}

\section{Plant culture}

Tobacco seeds ( N. tabacum L., 'K326') were germinated in a culture substrate (Ge et al., 2005) and grown to seedlings in a naturally illuminated greenhouse for 65 days. Then, 90 seedlings were transferred to plastic pots (diameter $=15 \mathrm{~cm}$; one plant per pot) containing peat moss mix, sand, and loam. The plants were watered every day with an excess of half-strength Hoagland nutrient solution and the draining solution was removed. The plants were kept in a greenhouse with day/night temperatures of $34 / 23^{\circ} \mathrm{C}$, relative humidity of $65-85 \%$, average photosynthetically active radiation (PAR) of $450 \mu \mathrm{mol} \cdot \mathrm{m}^{-2} \cdot \mathrm{s}^{-1}$, and a photoperiod of $14 \mathrm{~h} /$ day.

\section{UV-B treatments and harvest procedures}

Twenty-five days after transplantation, all plants were divided into three groups that were irradiated with different levels of UV-B. The UV-B radiation was artificially supplied by using UV-B emitting fluorescent lamps ( $30 \mathrm{~W}$, Nanjing Huaqiang Electronic Co., Nanjing City, Jiangsu Prov, China) based on the method described Ranjbarfordoei et al. (2009). The UV-B lamps were suspended above and perpendicular to the pots. The lamps were covered with $0.13 \mathrm{~mm}$ cellulose acetate (CA) film, to exclude UV radiation below $292 \mathrm{~nm}$. The CA films were changed every 2 days to avoid photodegradation of the CA properties caused by UV-B radiation. The density of UV-B irradiation above the plants was measured with a UV spectroradiometer (model UV-B, Photoelectric Instrument Factory of Beijing Normal University, Beijing City, China) and regulated by changing the distance between plants and lamps. The UV-B provided by sunlight was $75 \mu \mathrm{W} /$ $\mathrm{cm}^{2}$ (measured at 11:00 AM in June). The three UV-B exposure treatments used were: +0 (control), +9.75 (UV-B1), and $+20.76 \mu \mathrm{W} / \mathrm{cm}^{2}$ (UV-B2). These radiation densities are approximately equivalent to those recorded in China under clear-sky conditions in summer at elevations of 35, 1000, and $3000 \mathrm{~m}$ above sea level, respectively. No difference in PAR was observed among the three treatments. The plants were irradiated for $6 \mathrm{~h}$ per day in the middle of the photoperiod (10:00-16:00).

Plants were harvested before the onset of irradiation $(0 \mathrm{~d})$ and 6 hours $(1 / 4 \mathrm{~d})$, 1 day $(1 \mathrm{~d}), 2$ days $(2 \mathrm{~d}), 4$ days $(4 \mathrm{~d})$ and 8 days $(8 \mathrm{~d})$ after the irradiation started. Three independent plants were harvested from each treatment as replicates. Finally, 48 plants from all treatments were harvested, and the remaining plants were destroyed. The harvested samples were immediately frozen in liquid nitrogen and stored at $-70^{\circ} \mathrm{C}$ until laboratory analysis was performed.

Genetics and Molecular Research 16 (1): gmr16018438 


\section{Determination of carotenoids}

Carotenoids were extracted from lyophilized leaf samples $(0.5 \mathrm{~g})$ by using an acetone: water $(90: 10, \mathrm{v} / \mathrm{v})$ solution $(10 \mathrm{~mL})$ containing $0.1 \%$ butylated hydroxytoluene. Individual carotenoids (lutein and $\beta$-carotene) were analyzed via high performance liquid chromatography, using a Waters 2690 Alliance system according to the method described by Chu et al. (2010) with slight modifications. A reversed-phase $\mathrm{C}_{18}$ column $(3.9 \mathrm{~mm}$ i.d. $\mathrm{x} 150 \mathrm{~mm}, 5 \mu \mathrm{m})$ was used; elution was conducted using a mobile phase of (A) acetonitrile-water $(88: 12, \mathrm{v} / \mathrm{v})$ and (B) acetic ester with the following gradient elution: $0-10 \mathrm{~min}, 30 \% \mathrm{~A}+70 \% \mathrm{~B} ; 10-12 \mathrm{~min}$, $60 \% \mathrm{~A}+40 \% \mathrm{~B}$; and $12-30 \mathrm{~min}, 60 \% \mathrm{~A}+40 \% \mathrm{~B}$. The carotenoids were identified using a photodiode array detector (SPD-M10AVP, Shimadzu, Japan) at $450 \mathrm{~nm}$ by comparing the obtained spectra and retention times with those of references (Figure 1). Lutein and $\beta$-carotene standards were obtained from Sigma (St. Louis, MO, USA). Total carotenoid content was determined using a spectrophotometric method at $450 \mathrm{~nm}$. To prepare the calibration curve, we used $\beta$-carotene as the standard compound.

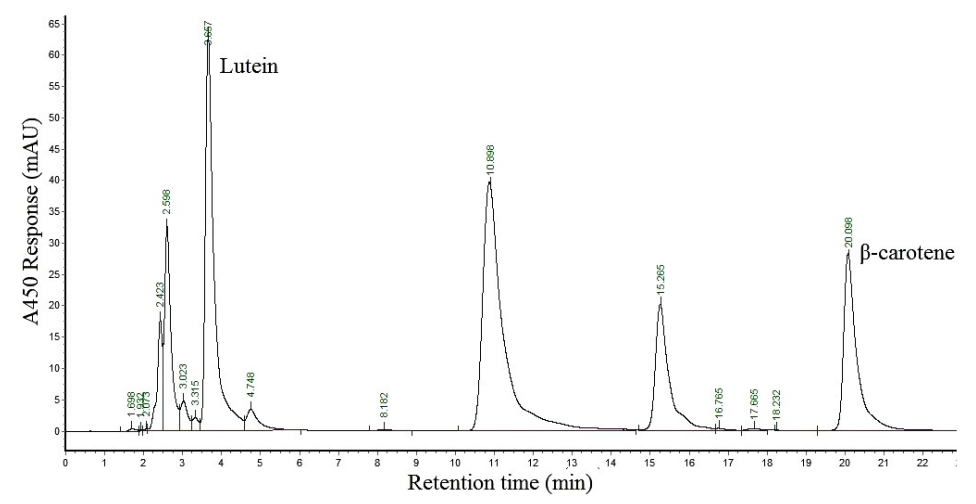

Figure 1. HPLC profiles of lutein and $\beta$-carotene.

\section{Estimation of $\mathrm{H}_{2} \mathrm{O}_{2}$}

$\mathrm{H}_{2} \mathrm{O}_{2}$ concentration was determined as described by Hichem et al. (2009). In brief, leaf samples $\left(0.5^{2} \mathrm{~g}\right)$ were homogenized in $5 \mathrm{~mL}$ cold acetone and centrifuged for $10 \mathrm{~min}$ at 1500 $g$. The supernatant was then used for the $\mathrm{H}_{2} \mathrm{O}_{2}$ assay. After 10 min reaction at $25^{\circ} \mathrm{C}, 0.1 \mathrm{~mL}$ $20 \% \mathrm{TiCl}_{4}$ and $0.2 \mathrm{~mL}$ concentrated ammonia were added to $1 \mathrm{~mL}$ supernatant. The reaction mixture was then centrifuged for $10 \mathrm{~min}$ at $1500 \mathrm{~g}$. Absorption was determined at $410 \mathrm{~nm}$ and $\mathrm{H}_{2} \mathrm{O}_{2}$ concentration was calculated according to the standard curve.

\section{Determination of $\mathrm{O}_{2}^{--}$}

A modified nitroblue tetrazolium (NBT) staining method was used to determine accumulated $\mathrm{O}_{2}^{-}$in the tested samples. This procedure was conducted based on the method described by Bournonville and Díaz-Ricci (2011) with slight modifications. In brief, detached leaves from tobacco seedlings were immersed in $50 \mathrm{mM}$ potassium phosphate buffer, $\mathrm{pH} 7.8$, containing $0.1 \%$ NBT and $10 \mathrm{mM}$ sodium azide. The leaves were infiltrated via vacuum shock 
for $2 \mathrm{~min}$, incubated for $2 \mathrm{~h}$ in the dark (without vacuum), and immersed in $96 \%(\mathrm{v} / \mathrm{v}$ ) ethanol to eliminate chlorophyll completely. $\mathrm{O}_{2}{ }^{--}$production was visualized as a purple formazan deposit in the leaf tissues. After NBT staining, the leaf tissues were dried with a heat gun and ground in a mortar. Formazan was extracted from $20 \mathrm{mg}$ dried tissue using $1 \mathrm{~mL} 2 \mathrm{M}$ potassium hydroxide:chloroform $(1: 1, \mathrm{v} / \mathrm{v})$, followed by complete drying under gaseous nitrogen flush at $4^{\circ} \mathrm{C}$ in the dark. The solid residue was then dissolved in $350 \mu \mathrm{L}$ dimethyl sulfoxide and 300 $\mu \mathrm{L} 2 \mathrm{M}$ potassium hydroxide and immediately analyzed with a spectrophotometer at $630 \mathrm{~nm}$. The quantification of formazan was calculated using the following equation:

$$
\text { Formazan }(\mu \mathrm{g})=\text { Absorbance }(630 \mathrm{~nm}) / 0.0174 \quad \text { (Equation 1) }
$$

The amount of $\mathrm{O}_{2}{ }^{--}$accumulated in the tested samples was expressed as $\mu \mathrm{g}$ formazan/mg dry weight.

\section{Trolox equivalent antioxidant capacity (TEAC) assay}

The leaf samples $(1 \mathrm{~g})$ were homogenized in an ice bath in $5 \mathrm{~mL}$ phosphate buffer (50 $\mathrm{mM}$ ), $\mathrm{pH} 7.2$, containing $1 \mathrm{mM}$ ethylenediaminetetraacetic acid (EDTA). The homogenized samples were centrifuged at $40,000 \mathrm{~g}$ for $25 \mathrm{~min}$ at $4{ }^{\circ} \mathrm{C}$, after which the supernatants were used for measurements. The principle of the 2,2'-azino-bis(3-ethylbenzothiazoline-6-sulfonic acid) (ABTS) assay is the scavenging mechanism of $\mathrm{ABTS}^{+}$radical by hydrogen-donating antioxidants in the sample, forming colorless ABTS (Majer et al., 2010). To form cation radicals, we mixed $0.1 \mathrm{mM}$ ABTS, $0.0125 \mu \mathrm{M}$ horseradish peroxidase, and $1 \mathrm{mM} \mathrm{H}_{2} \mathrm{O}_{2}$ with $50 \mathrm{mM}$ phosphate buffer, $\mathrm{pH}$ 6. After 15 min of incubation, $100 \mu \mathrm{L}$ leaf extract was added to $1 \mathrm{~mL}$ ABTS radical solution. The decrease in absorbance was determined at $730 \mathrm{~nm}$ after 2 min. The calibration curve was then drawn with Trolox, and the plant samples were expressed as $\mu \mathrm{g}$ Trolox equivalent $/ \mathrm{mL}$ leaf extract.

\section{Statistical analysis}

The results were statistically examined using one-way ANOVA, in which UV-B treatment and treatment time were used as factors. Their interactions were considered for the whole data set in SPSS for Windows v. 18.0 (standard version). Duncan's multiple-range test was used to compare the means at different levels within a specific factor. Three individual samples of each treatment were treated as replicates and subjected to statistical analysis $(\mathrm{N}=$ 3 for each treatment).

\section{RESULTS}

\section{Effects of UV-B radiation on the carotenoid content of tobacco leaves}

Lutein and $\beta$-carotene are the most abundant components of carotenoids in tobacco leaf. To examine the pattern of carotenoid accumulation in response to UV-B radiation, we determined the amounts of lutein, $\beta$-carotene, and total carotenoid in tobacco leaves. A dynamic change of carotenoid accumulation in the control and UV-B1-treated plants with a

Genetics and Molecular Research 16 (1): gmr16018438 
consistent increase throughout the study period is illustrated in Figure 2. However, carotenoid accumulation was higher in the UV-B1-treated than in the control plants from day 2 to day 8 . By contrast, the dynamic change of carotenoid content in the UV-B2-treated plants showed an inverted $\mathrm{V}$-shape. A significant $(\mathrm{P}<0.01)$ sharp increase was observed in the total carotenoid content on day 1 of treatment compared with the control plant (Figure 2A). Then, the total carotenoid content was reduced continually until day 4 . On day 8 , there was no significant difference in carotenoid contend between the UV-B2-treated and control plants $(\mathrm{P}>0.05)$. The same profile was observed in $\beta$-carotene contents in the UV-B2-treated group, but $\beta$-carotene was significantly lower $(7.74 \%, \mathrm{P}<0.05)$ than that of the control group on the last day (Figure 2B). The greatest increase $(54.22 \%, \mathrm{P}<0.01)$ in lutein content in the UV-B2-treated group was detected on day 2. At the end of the treatment, the lutein content in the UV-B2-treated group was significantly higher $(10.05 \%, \mathrm{P}<0.05)$ than that in the control group and slightly lower than that in the UV-B1-treated plants (Figure 2C).

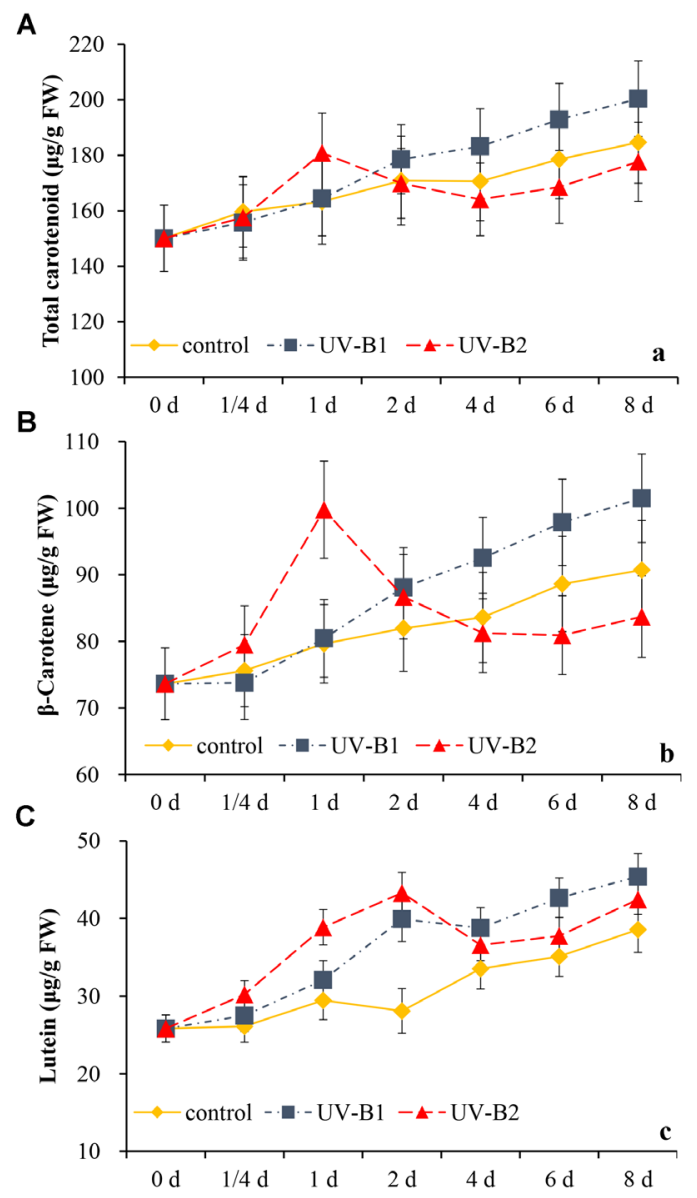

Figure 2. Effects of UV-B radiation on carotenoid content in tobacco seedling leaf. The leaves were harvested at different periods of exposure and the changes in total carotenoid (A), $\beta$-carotene (B), and lutein $(\mathbf{C})$ contents were measured in control, UV-B1-treated, and UV-B2-treated plants. Values are reported as means \pm SD of three independent replicates. FW means fresh weight.

Genetics and Molecular Research 16 (1): gmr16018438 


\section{Effects of UV-B radiation on ROS concentration in tobacco leaves}

The changes in ROS concentration $\left(\mathrm{H}_{2} \mathrm{O}_{2}\right.$ and $\left.\mathrm{O}_{2}{ }^{-}\right)$in tobacco leaves over time are shown in Figure 3. Both the $\mathrm{H}_{2} \mathrm{O}_{2}$ (Figure 3A) and $\mathrm{O}_{2}^{-{ }^{-}}$(Figure 3B) concentrations increased significantly in the UV-B1-treated group $(39.93$ and $53.55 \%$, respectively, $\mathrm{P}<0.01$ ) on day 1 compared with those in the control group. In this group, a relatively high level of ROS was maintained until day 8. In the UV-B2-treated plants, the generation of the two ROS increased sharply, reaching their maximum on day 1 . At this time point, the $\mathrm{H}_{2} \mathrm{O}_{2}$ concentration was $70.95 \%$ higher than the control group, whereas the $\mathrm{O}_{2}{ }^{--}$concentration was increased by more than one-fold compared to the control group. After day 1 , the $\mathrm{H}_{2} \mathrm{O}_{2}$ and $\mathrm{O}_{2}{ }^{-}$concentrations were reduced gradually followed by a levelling out after day 4 . After $8 \mathrm{~d}$ of UV-B exposure, the ROS levels in the leaves were higher compared with that observed in the control plants.

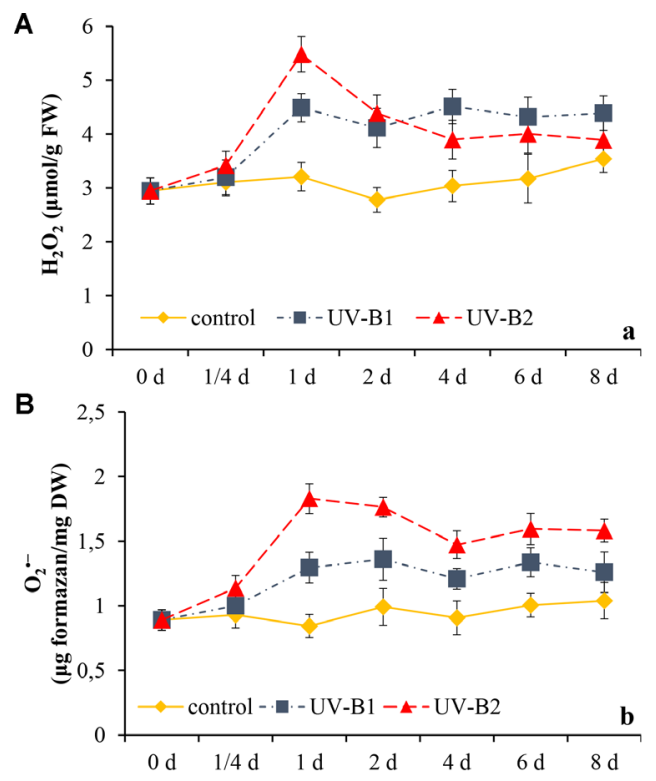

Figure 3. Effects of UV-B radiation on hydrogen peroxide $\left(\mathrm{H}_{2} \mathrm{O}_{2}\right)$ and superoxide anion $\left(\mathrm{O}_{2}{ }^{--}\right)$concentrations in tobacco seedling leaf. The leaves were harvested at different periods of exposure. Changes in $\mathrm{H}_{2} \mathrm{O}_{2}(\mathbf{A})$ and $\mathrm{O}_{2}{ }^{--}(\mathbf{B})$ concentration were measured in control, UV-B1-treated, and UV-B2-treated plants. Values are means \pm SD of three independent replicates. DW means fresh weight.

\section{Effects of UV-B radiation on TAC}

The leaf extract TAC was measured as the TEAC (Figure 4). In the UV-B1-treated group, the leaf TAC significantly increased after $4 \mathrm{~d}$ exposure. In the UV-B2-treated group, TAC increased immediately after the tobacco seedlings were exposed to high UV-B radiation. After the maximum peak, which was reached on 1/4 day, TAC decreased quickly and returned to the initial level after 2 days. On subsequent days, the changes in UV-B2 were similar to those of the UV-B1-treated group. After 8 days' exposure, a significantly higher TAC was observed in the UV-B-treated plants compared with the control plants $(\mathrm{P}<0.01)$. By contrast, no significant differences were found between the two UV-B treatment groups $(\mathrm{P}>0.05)$.

Genetics and Molecular Research 16 (1): gmr16018438 


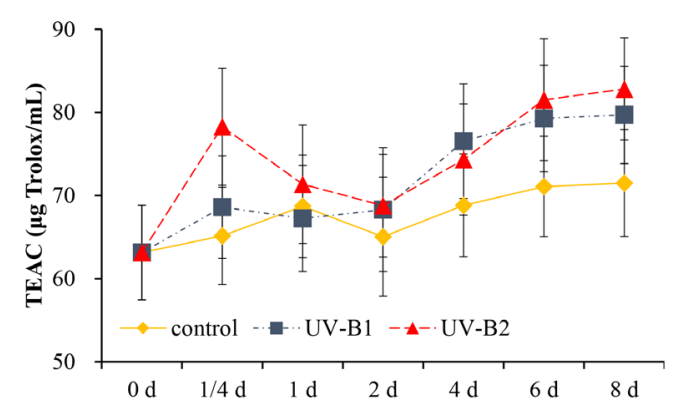

Figure 4. Changes in total antioxidant capacity (TAC) of tobacco seedlings during UV-B exposure. TAC was measured as the Trolox equivalent antioxidant capacity (TEAC) value of leaf extracts. The leaves were harvested at different periods of exposure. TEAC values were measured in control, UV-B1 treatment, and UV-B2 treatment plants. Values are reported as means $\pm \mathrm{SD}$ of three independent replicates.

\section{Correlation between carotenoid content and TAC}

The correlations between TAC and carotenoid content were characterized using Pearson's correlation coefficients $\left(r_{\mathrm{p}}\right.$; Table 1$)$. These analyses showed that TAC was positively correlated with lutein contents $(\mathrm{P}=0.002)$ and total carotenoid content $(\mathrm{P}=0.024)$. However, no correlation was found between TAC and $\beta$-carotene content $(\mathrm{P}>0.05)$.

Table 1. Pearson correlation coefficients $\left(r_{\mathrm{p}}\right)$ of lutein content, $\beta$-carotene content, total carotenoid content, and TEAC measured in tobacco leaves at different experimental times.

\begin{tabular}{l|c|c|c|c}
\hline$r_{\mathrm{P}}$ & Lutein & $\beta$-Carotene & Total carotenoid & TEAC \\
\hline Lutein & 1.00 & $0.80^{* *}$ & $0.82^{* *}$ & $0.65^{* *}$ \\
\hline$\beta$-Carotene & & 1.00 & $0.93^{* *}$ & 0.44 \\
\hline Total Carotenoid & & & 1.00 & $0.51^{*}$ \\
\hline TEAC & & & & 1.00 \\
\hline
\end{tabular}

$*, * *$ Significant correlations at 0.05 and 0.01 level, respectively.

\section{DISCUSSION}

ROS are products of normal cellular metabolism (Karuppanapandian et al., 2011). Under normal conditions, the ROS concentration in tobacco seedling leaves is constant. The stable state of ROS depends on the balance between ROS production and quenching by various enzymatic and non-enzymatic antioxidant systems (Dat et al., 2000). However, this delicate balance is perturbed by UV-B irradiation, thereby increasing ROS levels. The present study revealed an increase in $\mathrm{H}_{2} \mathrm{O}_{2}$ and $\mathrm{O}_{2}{ }^{-}$concentrations that was induced by UV-B irradiation. In plants treated with low levels of UV-B $\left(+9.75 \mu \mathrm{W} / \mathrm{cm}^{2}\right)$, the ROS concentration in the leaves increased by approximately $50 \%$ compared with that in the control group after 1 day. By contrast, ROS was increased remarkably (approximately one-fold) in plants treated with high levels of UV-B $\left(+20.76 \mu \mathrm{W} / \mathrm{cm}^{2}\right)$. The latter could be considered a "reactive oxygen burst" (Bhattacharjee, 2005). The overproduction of ROS in living organisms under stressful conditions is potentially toxic because ROS may attack biomolecules such as lipids, proteins, and DNA, as well as some small molecules. As a result, oxidative damage or even organism death may occur (Wang et al., 2013). To cope with ROS toxicity, plant cells use numerous 
highly efficient antioxidant systems comprised of enzymatic and non-enzymatic constituents (Carletti et al., 2003). As a result of these coping mechanisms, the ROS concentrations in the UV-B2-treated plants decreased on days 2-4 compared to the maximum on day 1, but they still remained higher than that of the control group.

Many studies have shown that plant carotenoid synthesis is increased by exposure to UV-B radiation, possibly because carotenogenesis is controlled by light quality as regulated by phytochrome and/or UV-B receptors (Mackerness, 2000; Becatti et al., 2009). In this study, the leaf carotenoid content increased after 2 days in the UV-B1 plants, compared with that in control plants. However, in the UV-B2 plants, a dynamic change in carotenoid content showing an inverted V-shape on days $0-4$ was observed. This dynamic change can be indicative of an increase in carotenoids that were oxidized by excess ROS induced by UV-B stress. Carotenoids have an important function by detoxifying various ROS forms and protecting photosynthetic organisms against oxidative damage (Karuppanapandian et al., 2011). The antioxidant properties of carotenoids are due to their conjugated double bonds (Ramel et al., 2012). Each double bond in the carotenoid backbone can be oxidized by ROS and subsequently produces various aldehydes and ketones (Kirakosyan et al., 2003; Ramel et al., 2012). The content of carotenoid oxidative degradation products in the tobacco leaves exposed to high UV-B radiation, including 6-methylhept-5-en-2-one, isophorone, damascenone, and geranyl acetone, was increased compared with that in the control group (Xue et al., 2016). Most of the carotenoid degradation products appear to be aromatic substances and the amounts of these products are an important quality index of some economic crops, such as flue-cured tobacco and tea.

The TAC of leaves is frequently included in the set of parameters used to characterize plant stress responses (Majer et al., 2010). In the present study, leaf TAC increased in both UV-B-treated groups, indicating that the tobacco antioxidant system was stimulated by UV-B radiation. Leaf TAC was remarkably altered after the plants were exposed to high UV-B radiation on day 1. Similar results were observed in Crataegus leaves subjected to drought and cold stress conditions (Kirakosyan et al., 2003). This substantial TAC increase in response to high UV-B radiation occurred before the reactive oxygen burst. This indicates that the antioxidant mechanism was activated rapidly in response to the environmental stressor to cope with oxidative damage.

The leaf TAC was positively correlated with lutein content $\left(r_{\mathrm{P}}=0.65, \mathrm{P}<0.01\right)$ and total carotenoid content $\left(r_{\mathrm{P}}=0.51, \mathrm{P}<0.05\right)$. This indicates that carotenoid accumulation helped the plant enhance the antioxidant capacity to reduce oxidative damage. The TAC/lutein correlation suggests that lutein is the most effective inhibitor. This result is consistent with that of Sindhu et al. (2010), who found that lutein contains conjugated double bonds and two hydroxyl groups on both ends; this structure results in a stronger antioxidant than other carotenoids.

Our results indicate an increase in carotenoids induced by UV-B radiation that enhances the TAC of antioxidant system and prevents the tobacco plant from photooxidative destruction. However, whether this induced response could prevent plants from oxidative damage caused by other environment stressors, such as drought, high temperature, or salt, is not known. Further studies are needed to fully understand the impacts of UV-B exposure on plant resistance to environment stressors.

\section{Conflicts of interest}

The authors declare no conflict of interest.

Genetics and Molecular Research 16 (1): gmr16018438 


\section{ACKNOWLEDGMENTS}

Research supported by the project of Anhui Province Caramel Flavor Tobacco Leaf Development (\#2011051011) and the Research of The Obstacle Factor of Potassium Uptake in Tobacco Leaves (\#16B0918).

\section{REFERENCES}

Ballach HJ, Mooi J and Wittig R (1992). Premature aging in Populus nigra L. after exposure to air pollutants. J. Appl. Bot. Food Qual. 66: 14-20.

Becatti E, Petroni K, Giuntini D, Castagna A, et al. (2009). Solar UV-B radiation influences carotenoid accumulation of tomato fruit through both ethylene-dependent and -independent mechanisms. J. Agric. Food Chem. 57: 10979-10989. http://dx.doi.org/10.1021/jf902555x

Bhattacharjee S (2005). Reactive oxygen species and oxidative burst: Roles in stress, senescence and signal transduction in plants. Curr. Sci. 89: 1113-1121.

Bournonville CF and Díaz-Ricci JC (2011). Quantitative determination of superoxide in plant leaves using a modified NBT staining method. Phytochem. Anal. 22: 268-271.http://dx.doi.org/10.1002/pca.1275

Bouvier F, Backhaus RA and Camara B (1998). Induction and control of chromoplast-specific carotenoid genes by oxidative stress. J. Biol. Chem. 273: 30651-30659. http://dx.doi.org/10.1074/jbc.273.46.30651

Brosché M and Strid Å (2003). Molecular events following perception of UV-B radiation by plants. Physiol. Plant. 117: 1-10. http://dx.doi.org/10.1034/j.1399-3054.2003.1170101.x

Carletti P, Masi A, Wonisch A, Grill D, et al. (2003). Changes in antioxidant and pigment pool dimensions in UV-B irradiated maize seedlings. Environ. Exp. Bot. 50: 149-157. http://dx.doi.org/10.1016/S0098-8472(03)00020-0

Chu DY, Xie YQ, Hong SQ, Yan X, et al. (2010). Major carotenoids in tobacco laminas: Identification and quantification by HPLC with photodiode array detection. Asian J. Chem. 22: 2635-2647.

Dat J, Vandenabeele S, Vranová E, Van Montagu M, et al. (2000). Dual action of the active oxygen species during plant stress responses. Cell. Mol. Life Sci. 57: 779-795. http://dx.doi.org/10.1007/s000180050041

Fedina I, Velitchkova M, Georgieva K, Demirevska K, et al. (2007). UV-B response of green and etiolated barley seedlings. Biol. Plant. 51: 699-706. http://dx.doi.org/10.1007/s10535-007-0145-2

Ge S, Cheng X, Xue Z, Yang L, et al. (2005). b-Aminobutyric acid-mediated enhancement of resistance in tobacco against TMV and consideration of its capability in wounded tobacco plants. Indian J. Biochem. Biophys. 42: 166-172.

Hichem H, Mounir D and Naceur EA (2009). Differential responses of two maize (Zea mays L.) varieties to salt stress: Changes on polyphenols composition of foliage and oxidative damages. Ind. Crops Prod. 30: 144-151. http://dx.doi. org/10.1016/j.indcrop.2009.03.003

Hideg E (2006). Detecting stress-induced reactive oxygen species in plants under UV stress. In: Environmental UV radiation: Impact on ecosystems and human health and predictive models (Ghetti F, Checcucci G and Bornman JF, eds.). Springer, Amsterdam, 147-157.

Indrajith A and Ravindran KC (2009). Antioxidant potential of Indian medicinal plant on Phyllanthus amarus L. under supplementary UV-B radiation. Recent Res. Sci. Technol 1: 34-42.

Juozaitytė R, Ramaškevičienė A, Sliesaravičius A, Burbulis N, et al. (2008). Effects of UVB radiation on photosynthesis pigment system and growth of pea (Pisum sativum L.). Sci Works Lithuanian Inst. Hortic. Lithuanian Univ. Agric 27: 179-186.

Karuppanapandian T, Moon JC, Kim C, Manoharan K, et al. (2011). Reactive oxygen species in plants: Their generation, signal transduction, and scavenging mechanisms. Aust. J. Crop Sci 5: 709-725.

Kirakosyan A, Seymour E, Kaufman PB, Warber S, et al. (2003). Antioxidant capacity of polyphenolic extracts from leaves of Crataegus laevigata and Crataegus monogyna (Hawthorn) subjected to drought and cold stress. J. Agric. Food Chem. 51: 3973-3976. http://dx.doi.org/10.1021/jf030096r

Lidon FJC (2012). Micronutrients' accumulation in rice after supplemental UV-B irradiation. J. Plant Interact. 7: 19-28. http://dx.doi.org/10.1080/17429145.2011.574214

Mackerness SAH (2000). Plant responses to ultraviolet-B (UV-B: 280-320 nm) stress: What are the key regulators? Plant Growth Regul. 32: 27-39. http://dx.doi.org/10.1023/A:1006314001430

Majer P, Stoyanova S and Hideg E (2010). Do leaf total antioxidant capacities (TAC) reflect specific antioxidant potentials? - A comparison of TAC and reactive oxygen scavenging in tobacco leaf extracts. J. Photochem. Photobiol. B 100: 38-43.http://dx.doi.org/10.1016/j.jphotobiol.2010.04.007

Genetics and Molecular Research 16 (1): gmr16018438 
Neill S, Desikan R and Hancock J (2002). Hydrogen peroxide signalling. Curr. Opin. Plant Biol. 5: 388-395. http://dx.doi. org/10.1016/S1369-5266(02)00282-0

Pallet KE and Young AJ (1993). Carotenoids. In: Antioxidants in higher plants (Alscher RG and Hess JL, eds.). CRC Press, Boca Raton, 59-90.

Polle A, Mossnang M, Von Schonborn A, Sladkovic R, et al. (1992). Field studies on Norway spruce trees at high altitudes. I. Mineral, pigment and soluble protein contents of needles as affected by climate and pollution. New Phytol. 121: 89-99. http://dx.doi.org/10.1111/j.1469-8137.1992.tb01096.x

Ramel F, Birtic S, Ginies C, Soubigou-Taconnat L, et al. (2012). Carotenoid oxidation products are stress signals that mediate gene responses to singlet oxygen in plants. Proc. Natl. Acad. Sci. USA 109: 5535-5540. http://dx.doi. org/10.1073/pnas.1115982109

Ranjbarfordoei A, van Damme P and Samson R (2009). Elevated ultraviolet-B radiation influences photosynthetic pigments and soluble carbohydrates of sweet almond. Electron. J. Environ. Agric. Food Chem 8: 1077-1084.

Salama HMH, Al Watban AA and Al-Fughom AT (2011). Effect of ultraviolet radiation on chlorophyll, carotenoid, protein and proline contents of some annual desert plants. Saudi J. Biol. Sci. 18: 79-86. http://dx.doi.org/10.1016/j. sjbs.2010.10.002

Sindhu ER, Preethi KC and Kuttan R (2010). Antioxidant activity of carotenoid lutein in vitro and in vivo. Indian J. Exp. Biol. 48: 843-848.

Singh R, Singh S, Tripathi R and Agrawal SB (2011). Supplemental UV-B radiation induced changes in growth, pigments and antioxidant pool of bean (Dolichos lablab) under field conditions. J. Environ. Biol. 32: 139-145.

Strid A, Chow WS and Anderson JM (1994). UV-B damage and protection at the molecular level in plants. Photosynth. Res. 39: 475-489. http://dx.doi.org/10.1007/BF00014600

Wang B, Sun YF, Song N, Wang XJ, et al. (2013). Identification of UV-B-induced microRNAs in wheat. Genet. Mol. Res. 12: 4213-4221. http://dx.doi.org/10.4238/2013.October.7.7

Xue BY, Shen J, Jiang CQ, Zu CL, et al. (2016). Influence of two typical environments on flavor type and aroma substances of flue-cured tobacco. Chin. Tobacco Sci 37: 1-7.

Zlatev ZS, Lidon FJC and Kaimakanova M (2012). Plant physiological responses to UV-B radiation. Emir. J. Food Agric. 24: 481-501. http://dx.doi.org/10.9755/ejfa.v24i6.481501

Genetics and Molecular Research 16 (1): gmr16018438 